\title{
Priming primary care providers to engage in evidence-based discussions about cannabis with patients
}

\author{
Devan Kansagara ${ }^{1,2^{*}}$, William C. Becker ${ }^{3,4}$, Chelsea Ayers ${ }^{1}$ and Jeanette M. Tetrault ${ }^{3}$
}

\begin{abstract}
Cannabis use has become increasingly common in the U.S. in recent years, with legalization for medical and recreational purposes expanding to more states. With this increase in use and access, providers should be prepared to have more conversations with patients about use. This review provides an overview of cannabis terminology, pharmacology, benefits, harms, and risk mitigation strategies to help providers engage in these discussions with their patients. Current evidence for the medical use of cannabis, cannabis-related diagnoses including cannabis use disorder (CUD) and withdrawal syndromes, and the co-use of opioids and cannabis are discussed. It is crucial that providers have the tools and information they need to deliver consistent, evidence-based assessment, treatment, prevention and harmreduction, and we offer practical guidance in these areas.
\end{abstract}

Keywords: Cannabis, Provider-patient relationship, Medical marijuana, Risk mitigation, Mental health, Substance use

\section{Introduction}

Cannabis use has become more accepted by society over the last two decades, and legalization is now supported by a majority of Americans [1]. Currently 33 states and the District of Columbia (DC) have legalized cannabis for certain medical indications, and in 10 of these states plus DC, it is legal for recreational use [2]. The prevalence of cannabis use has increased in recent years, with past-month use in the United States (U.S.) increasing from 5.8 to $8.4 \%$ between 2007 and 2014 [3]. Over 90\% of individuals who use cannabis report recreational use, though many patients do not draw a clear distinction between medical and recreational use $[4,5]$. The prevalence of frequent cannabis use has also increased over time; from 2002 to 2014, the prevalence of past-year daily cannabis use in the U.S. increased from 1.3 to $2.5 \%$ [6]. Increasingly, providers are likely to encounter patients who use cannabis, or who have questions about cannabis use. Thus, in this review article, we aim to provide

\footnotetext{
*Correspondence: kansagar@ohsu.edu

1 VA Evidence Synthesis Program, VA Portland Healthcare System, Mail Code R\&D 71, 3710 SW US Veterans Hospital Road, Portland, OR 97239-2999, USA

Full list of author information is available at the end of the article
}

information about terminology, pharmacology, benefits, harms, and risk mitigation strategies to help providers frame these discussions.

\section{Terminology, pharmacology, and formulations}

The two main classes of compounds in the cannabis plant flower are cannabinoids and terpenes. There are over 100 cannabinoids, but the best studied are delta-9-tetrahydrocannabinol (THC) and cannabidiol (CBD). The effects of cannabis on the body and mind are mediated through the endocannabinoid system, which includes receptors (CB1 and 2) found throughout the body [7]. CB1 receptors are highly concentrated in the brain, though not in the lower brainstem which may explain why cannabis has not been associated with respiratory depression $[8,9]$. Most of the psychogenic effect-or the "high" - of cannabis is mediated through the interaction of THC with the $\mathrm{CB} 1$ receptor. On the other hand, CBD does not cause potent psychogenic effects due to its low binding affinity for CB1; it also has lowbinding affinity for CB2. Terpenes have been largely unstudied, but contribute the aroma and flavor of cannabis and are thought to potentially influence the psychogenic effects of the cannabinoids [7]. The term cannabis is typically used when referring to the 
whole plant or extracts of the whole plant, while the term cannabinoids is used to refer to plant extraction or synthetic products that are isolates of THC, CBD, or a combination of the two.

Cannabis is available and used in many forms. The flower of the plant is the most commonly used form, and there are also numerous plant extract formulations including edibles, resins, oils, tinctures, oromucosal sprays, and topical applications (see Table 1). Two synthetic cannabinoids-dronabinol and nabilone-are FDA-approved for use in chemotherapy induced nausea and vomiting, and AIDS-related cachexia, and one recently-FDA-approved drug, Epidiolex ${ }^{\circledR}$, used for rare forms of seizure disorders, contains CBD extracted from cannabis plants [10].

There are two main subspecies of the Cannabis sativa plant-Sativa and Indica-though they are largely now indistinguishable because of extensive cross breeding over time [11]. These terms are used colloquially to characterize the expected effects of a given product: Sativa products are purported to have energizing, uplifting, and creative effects (a "mind high"), while Indica strains tend to be sedating, and relaxing physically and mentally (a "body high"). While these terms are commonly used, they are not scientifically grounded. The degree to which a product will have energizing, intoxicating, or relaxing effects is most likely determined by the relative amounts of THC and CBD in the product [3].

There are three main routes of administration: inhalation, ingestion, and topical application (see Table 2 for a summary of the pharmacokinetics and side effects for each) [7]. Smoking and vaping produce rapid peaks in central nervous system THC concentration, and the duration of peak effect is often limited to 30-60 min. "Dabbing," another method of inhalation, refers to the flash vaporizing of hash oil that is extracted with chemicals like butane and concentrated into a wax or resin that is smoked, produces very high concentrations of THC and an intense intoxicating effect [12]. On the other hand, with the ingestion of edibles (e.g. brownies, cookies, candies, etc.) the peak effect is delayed, often for $2-3 \mathrm{~h}$ or more, and the duration of effect is longer. Furthermore, the oral metabolite of THC, 11-hydroxy-THC, is several-fold more potent in its psychogenic effect than THC. Taken together, these characteristics of cannabis edibles explain their role in numerous case reports of acute cannabis-induced psychosis requiring hospitalization after cannabis naïve patients took repeat doses of cannabis edibles because they did not feel an initial effect $[13,14]$. Topical applications of cannabis are also widely available but have not been well studied. While they are thought to be associated with minimal systemic absorption and to have lower potential for central nervous system effects, there is little empiric data documenting the potential benefits and harms of topical preparations.

The potency of cannabis is typically defined as the amount of THC in the product. Given the innumerable formulations and strengths of cannabis available today, it is challenging to define the average potency of cannabis patients will encounter. Moreover, the THC concentration of cannabis has changed over time. For example, the THC concentration of black-market cannabis increased threefold, from 4 to $12 \%$, over the last two decades. Several states have defined a "dose" of THC as 5-10 mg [3].

Table 1 Cannabis formulations and routes of administration

\begin{tabular}{|c|c|c|c|}
\hline Form & Other terms & Development & Route of administration \\
\hline Plant & Flower, bud & $\begin{array}{l}\text { The highest concentration of cannabinoids are found in the } \\
\text { flower, not the leaf, of the female plant }\end{array}$ & Smoking Vaporization Topical Rectal \\
\hline Edibles & Brownies, cookies, candy & $\begin{array}{l}\text { Typically butter or oil used to extract cannabinoids and put } \\
\text { into a variety of edible products }\end{array}$ & Oral \\
\hline Tincture & Golden dragon, green dragon & Alcohol or glycerin used to extract active ingredients & Oral Sublingual Oromucosal \\
\hline Oil & & Alcohol used to make highly viscous concentrated extract & Oral Topical \\
\hline Resin & Hash, dry sift, kief & $\begin{array}{l}\text { Concentrate made by mechanically separating trichomes } \\
\text { (hair-like protrusions on flower with high concentration of } \\
\text { cannabinoids) from the plant }\end{array}$ & Smoking Vaporization \\
\hline Dab & Wax, shatter & $\begin{array}{l}\text { Ultraconcentrated extract made with solvents such as } \\
\text { butane; very high levels of THC, potentially dangerous }\end{array}$ & $\begin{array}{l}\text { Dabbing (concentrate placed on a } \\
\text { very metal rod and inhaled) }\end{array}$ \\
\hline Nabiximols & Sativex & $\begin{array}{l}\text { Pharmaceutically prepared whole plant extract in spray form; } \\
\text { 1:1 THC:CBD concentration; approved for use in the EU }\end{array}$ & Oromucosal \\
\hline $\begin{array}{l}\text { Pharmaceuti- } \\
\text { cal cannabi- } \\
\text { noids }\end{array}$ & Dronabinol, Nabilone, Epidiolex ${ }^{\circledR}$ & $\begin{array}{l}\text { Dronabinol and nabilone are FDA-approved synthetic THC } \\
\text { (chemotherapy induced nausea/ vomiting; AIDS related } \\
\text { cachexia); Epidiolex }{ }^{\circledR} \text { is a highly purified CBD plant extract } \\
\text { and is FDA-approved for the treatment of two rare epilepsy } \\
\text { syndromes }\end{array}$ & Oral \\
\hline
\end{tabular}




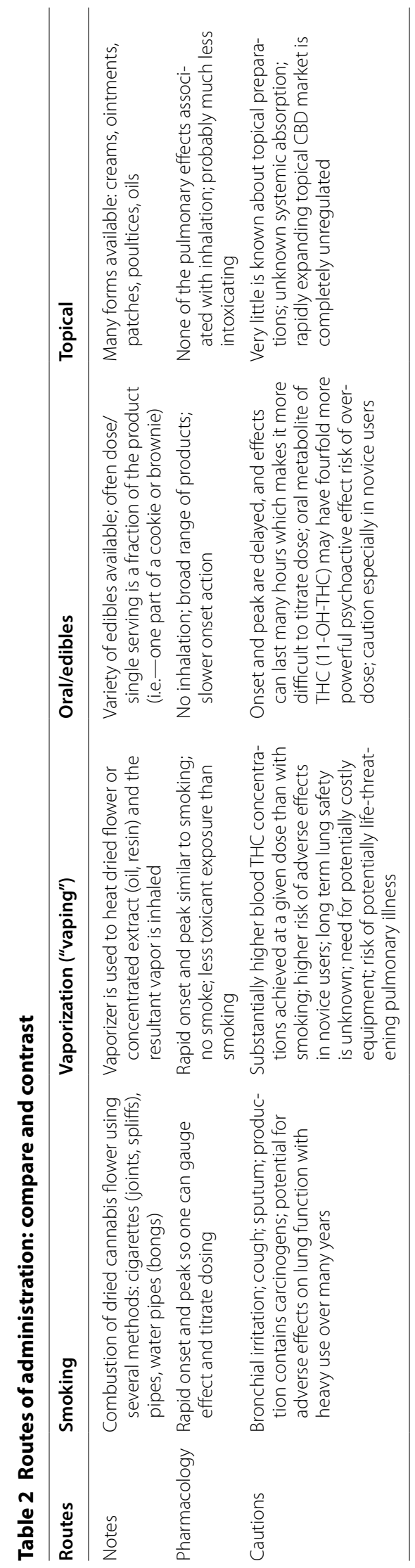


The average cannabis cigarette (i.e., joint) weighs about 0.32 to $0.66 \mathrm{~g}[15,16]$. High potency products in dispensaries can contain $15-20 \%$ THC, so the amount of THC in a high potency product might be anywhere from 48 to $132 \mathrm{mg}$. In a recent study of dispensaries in several states, the median amount of THC in a 1.5-g edible product was $54 \mathrm{mg}$, and the median THC:CBD ratio was 36:1 [17].

Of note, cannabis product labels are often inaccurate. One multi-state study examining THC content of edible products sold in cannabis dispensaries found that only $17 \%$ of product labels were accurate when compared to lab measured content [17]. CBD extracts are available over the counter in many locations, as well as online. A study of 84 CBD products purchased online found that only $31 \%$ were labeled accurately [18]. In $21 \%$ of the CBD products, THC was detected, often in concentrations high enough to produce intoxication, especially in children [18] (which underscores the need to store all cannabis products, including CBD products, out of the reach of children).

\section{Cannabis for medical use}

Medical cannabis laws and implementation of programs vary greatly by state, but in many states with medical cannabis laws, physicians can "certify" that a patient has a condition for which cannabis has been indicated and state-administered programs grant certified patients medical cannabis "cards" [2]. The medical cannabis card then allows patients to enter medical cannabis dispensaries where an employee (often referred to as a "budtender" [19]) discusses the various available products. However, most budtenders have little or no medical training [20]. Most of these states also allow limited home cultivation of cannabis for medical purposes. In states in which cannabis is recreationally legal (all of which also have medical cannabis laws), the medical and recreational dispensaries are often in the same store. Of the states with medical cannabis laws, most have legalized cannabis for the following indications: chronic pain, muscle spasticity and/or multiple sclerosis, epilepsy, anorexia/cachexia, HIV/AIDS, glaucoma, cancer, inflammatory bowel disease, and post-traumatic stress disorder (PTSD) [21]. In a recent nationwide review of state registry data, the most commonly listed qualifying conditions for medical cannabis certification were chronic pain, followed by multiple sclerosis, nausea, cancer, then PTSD [22]. Additionally, one survey study in California found that the most common self-reported indications for cannabis use were anxiety, chronic pain, stress, insomnia, and depression [23].

There are many gaps in the evidence examining the health effects of cannabis, though the literature is expanding rapidly. Many studies have been conducted outside the U.S. in part because of regulatory hurdles associated with the status of cannabis as a Schedule 1 controlled substance at the federal level, which designates it as having "no currently accepted medical use and a high potential for abuse" [24]. A recent National Academy of Sciences report provided a broad and high-level overview of contemporary knowledge about the pharmacology, regulation, benefits, and harms of cannabis for a variety of conditions [3]. It concluded that there is "substantial evidence that cannabis is an effective for chronic pain in adults." [3]. However, the report did not distinguish the evidence for different types of chronic pain, did not use standard systematic review methods and terminology, and also cautioned that little was known about the efficacy and dosing of cannabis preparations available in the United States.

Two recent systematic reviews that focused on the effects of cannabis for chronic pain found limited evidence that cannabis is effective for neuropathic pain (i.e. pain from peripheral or central nervous system lesions) and for multiple sclerosis-related pain and spasticity in studies of short duration, but insufficient evidence to draw conclusions about the effects of cannabis on nociceptive pain (i.e. pain from tissue damage such as from inflammation, trauma or arthritis) [25, 26]. In placebocontrolled trials of patients with neuropathic pain from a variety of causes, cannabis was associated with a small reduction in pain (about 1 point on a 10-point visual analog scale), and more patients treated with cannabis experienced a $30 \%$ or more improvement in neuropathic pain than those assigned to placebo [25]. In patients with multiple sclerosis, cannabis formulations with a combination of THC/CBD in a 1:1 or 2:1 ratio were associated with improvements in pain and spasticity at up to 12-15 weeks of follow up $[25,27]$. However, there are numerous limitations to this evidence base. First, findings were not consistent across studies. Second, most studies showing benefit reported outcomes after only a matter of hours to days with the longest study being 15 weeks. Providers should be cautious in extrapolating data from short-term studies to the management of chronic pain, which often requires treatment for many months. Third, the formulations tested differed across studies, and often differed from formulations that are commonly available to, and used by, patients in dispensaries [25]. For example, the best studied formulation of cannabis is nabiximols, a cannabis extract that comes as an oromucosal spray of $2.5 \mathrm{mg} \mathrm{THC} / 2.5 \mathrm{mg}$ CBD; while it is licensed in other parts of the world, it is not available in the U.S. In studies that showed a benefit from nabiximols, participants used an average of $25 \mathrm{mg}$ of THC over $24 \mathrm{~h}$ [25].

Oral cannabinoids may improve chemotherapy-induced nausea and vomiting [3]. The 
synthetic, prescription cannabinoids nabilone and dronabinol appear to be as effective in reducing chemotherapy induced nausea and vomiting as older prescription anti-emetics, but the evidence is limited by methodologic flaws, and not representative of currently available antiemetics and chemotherapeutic regiments. The authors of one review cautiously suggest cannabinoids may be a reasonable second-line option for patients who have failed or cannot tolerate conventional anti-emetics [28].

There are numerous clinical conditions for which cannabis or cannabinoids have been considered or even approved for use at the state level despite a lack of controlled studies in many cases. There is largely insufficient evidence to support or refute the effectiveness of cannabis and/or cannabinoids for the following conditions: irritable bowel syndrome, amyotrophic lateral sclerosis, Parkinson's disease, dystonia, post-traumatic stress disorder, and glaucoma. There are very few high-quality studies examining the effects of cannabis and oral cannabinoids on weight loss and anorexia associated with HIV/AIDS and cancer. While there is insufficient evidence for the effectiveness of cannabis or cannabinoids for most forms of epilepsy, the FDA recently approved a highly purified CBD plant extract called Epidiolex ${ }^{\circledR}$ for the treatment of two rare childhood-onset epilepsy syndromes on the basis of trials showing significant reduction in seizure frequency $[29,30]$. There has been increased interest in additional potential therapeutic effects of CBD alone, in part because it is viewed as likely to have a more favorable adverse effect profile than THC-containing products. While there is not conclusive evidence supporting the health effects of CBD preparations beyond the epilepsy syndromes mentioned above, a growing body of evidence suggests CBD may have potential as an anxiolytic agent, though further research is needed [31, 32].

\section{Potential harms of cannabis use \\ Cannabis and other substance use disorders}

Cannabis use is associated with the development of a cannabis use disorder (CUD), characterized by craving, tolerance, withdrawal, and continued use despite adverse social, vocational, or legal consequences of use (see Table 3) [33]. Authors examining data from multiple waves of the National Epidemiologic Survey on Alcohol and Related Conditions (NESARC) sought to determine the association of cannabis use with subsequent mental health and substance use disorders and found that among survey participants with past-year cannabis use, 36\% met criteria for CUD; among those reporting cannabis use in wave 1 , the incidence of CUD 7 to 8 years later was $25 \%$ [34]. Nearly half of those with CUD had moderate to severe disease, and men, lowincome participants, adolescents and young adults were

\section{Table 3 Stepwise assessment of cannabis use disorder}

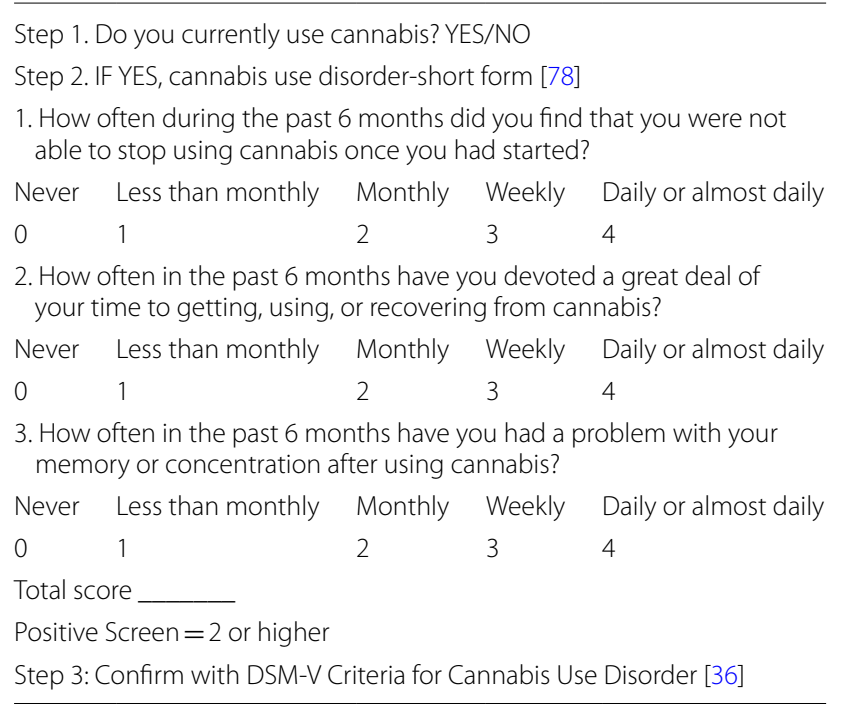

at highest risk of developing CUD [35]. Indeed, the risk of CUD was up to $50 \%$ greater among individuals who used daily and initiated use in adolescence $[34,36]$.

Cannabis withdrawal is now considered a Diagnostic and Statistical Manual (DSM)-5 syndrome and is associated with symptoms that may develop up to 1 week after cannabis cessation and last up to several weeks [33]. Many of the symptoms of cannabis withdrawal such as anxiety, depression and insomnia overlap with symptoms that patients may be using cannabis to alleviate in the first place, which underscores the need for the public and providers to be aware of this withdrawal syndrome.

Cannabis use is not only associated with increased risk of CUD, but also with a sixfold increase in risk of developing any substance use disorder (SUD) [34]. From an emerging body of evidence with mixed findings it is unclear whether those using cannabis only for medical purposes have a different risk of CUD and SUD from those using for recreational purposes [37, 38].

\section{Other mental health harms}

Substantial evidence suggests an association between cannabis use and the development of psychotic symptoms, with increasing risk among individuals with more frequent cannabis use [25, 39]. Consumption of a large amount of THC can cause acute psychosis, but there is also data that regular cannabis use-especially in young adults and among those with a genetic predisposition to schizophrenia-is associated with the development of chronic psychosis $[39,40]$. It is unclear whether cannabis use is associated with other mental health outcomes such as suicidal ideation, depression, anxiety, and mania $[3,25]$. 
A large and growing body of evidence demonstrates an association between active, long-term cannabis use and small but significant negative effects on all domains of cognitive function, though it is unclear whether cognitive deficits persist in those who have stopped using cannabis [25, 39]. Concerns for cognitive dysfunction are magnified in adolescents with cannabis use because brain development continues into young adulthood. Findings from a birth cohort study suggested that ongoing cannabis use during adolescence is associated with neuropsychological decline broadly across domains of functioning, even after controlling for years of education. The study also found that cessation of cannabis use did not fully attenuate cognitive decline in adulthood [41]. Other studies focus more on the acute neuropsychological implications of cannabis use. The National Institute of Health (NIH) is currently embarking on a large population study, The Adolescent Brain Cognitive Development (ABCD) Study, which will add significantly to the evidence base in this area [42].

\section{Physical health harms}

The literature does not show a direct association between prolonged cannabis use and measures of airflow obstruction or development of lung cancer [25]. There are data suggesting respiratory harms in those with frequent smoked cannabis use (i.e. more than weekly), in older adults, and those with medical comorbidities [25]. A few large epidemiologic studies suggest that prolonged daily cannabis smoking may be associated with a decline in lung function over two decades, and systematic reviews note an association between cannabis smoking and symptoms of chronic bronchitis [3, 43, 44]. An emerging case series of severe pulmonary illness associated with inhalation of vaporized products typically bought illicitly, and often containing THC, has recently been described [45]. The cause is unclear, but is thought to be related to chemicals in vaping products or equipment, [45] and underscores the uncertainty and potential danger of vaporizing unregulated cannabis products.

While cannabis can increase heart rate, supine blood pressure, and postural hypotension, there is insufficient evidence to draw conclusions about its effects on cardiovascular health outcomes $[46,47]$. There is likewise insufficient evidence examining effects on most types of cancer [25].

Driving under the influence of cannabis poses significant public health risks. Systematic reviews and metaanalyses suggest a low-to-moderate association between cannabis use and motor vehicle crashes, even when accounting for alcohol or other substance use [48, 49]. Most of the studies included in these reviews are casecontrol studies or culpability studies; therefore, more research is needed to understand the complex relationship between driving under the influence of cannabis and vehicular injuries especially as more states enact recreational cannabis legislation.

Cannabis hyperemesis syndrome is a form of cyclic vomiting that is thought to be associated with chronic, regular cannabis use [50]. Most patients also present with abdominal pain and many patients report improvement of symptoms with hot showers [50]. The treatment is discontinuation of cannabis, though improvement may take many weeks and the effectiveness of abstinence has not been well studied [50]. There are a variety of case series suggesting potential efficacy for a variety of pharmacotherapies, though there are no trial data to guide treatment choice [51].

Another concern regarding recreational cannabis laws is the risk of pediatric exposure and overdose, especially related to edible products. In states that have enacted medical and recreational cannabis laws, the absolute number of hospitalizations and poison control center calls are low, but the rates of unintentional pediatric exposures continue to increase compared with states that have not enacted these laws [52-54]. This should prompt policymakers to pass more stringent regulations regarding cannabis product packaging, labeling and marketing.

\section{Synthetic cannabinoid harms}

Synthetic cannabinoids are man-made cannabis derivatives often marketed as safe, legal alternatives especially in states without recreational cannabis laws. The route of administration is most often inhaled, but they can be ingested as well. They are often substantially more potent CB1 receptor agonists than plant-derived THC [55]. Clinical effects may be similar to intoxication with cannabis but may present more acutely and include tachycardia, vomiting, ataxia, violent behavior, suicidal ideation, sedation, and slurred speech. There have been case reports and case series of "outbreaks" of mass intoxication with synthetic cannabinoids such as FUBINACA and $\mathrm{K} 2$ [55-57].

\section{Cannabis and opioids}

Pain is a leading symptom driving non-recreational cannabis use, whether medically authorized or not. Despite recent efforts to reduce prescribed opioid therapy for pain in the U.S., and to increase treatment for opioid use disorder (OUD), opioids remain a prominent treatment for both acute and chronic pain, and untreated illicit opioid use has reached epidemic levels [58]. Given widespread opioid and cannabis use, both illegal and prescribed, cannabis and opioid co-use is increasingly common. 


\section{Potential benefits of co-use, opioid sparing effects}

Widely-cited ecological studies have demonstrated an association between states allowing medical and/or recreational cannabis use and declining opioid prescription [59]. OUD hospitalization [60] and overdose rates [61] driving a hypothesis that opioid users may be substituting cannabis and decreasing risky opioid use. However, a more recent analysis demonstrated increased rates of opioid overdose death among states with more liberal cannabis laws, including those permitting recreational cannabis use [62]. At the individual level, there are studies suggesting that cannabis augments the analgesia produced by opioids, $[63,64]$ potentially allowing opioid dose-lowering, thus possibly enhancing safety. One cross-sectional study of 244 individuals with chronic pain who were receiving cannabis from a dispensary found that these individuals reported decreased opioid use over time because of the benefits of cannabis for pain [65]. An ongoing online survey of 1321 participants, found 53\% reported substituting cannabis for opioids, citing fewer side effects and better symptom management as their rationale for doing so [66]. Prospective, individual-level studies are needed to examine cannabis' potential role as an opioid sparing agent.

\section{Potential harms of co-use}

With respect to overdose, the most common opioidrelated cause of death, there is a dearth of data on the potential additive risk of cannabis co-use [67]. As for non-overdose harms, the synergistic effects on psychomotor slowing, depressed sensorium, and delirium (neurocognitive effects) of co-use may lead to increased risk of motor vehicle accidents, falls, and trauma, all known dose-dependent risks of opioids by themselves [67, 68]; more epidemiologic studies are needed. With respect to concerns of association with SUD, observational data suggest that cannabis use is associated with opioid misuse among patients on long-term opioid therapy [69] with a more recent study demonstrating nearly sixfold increased odds of non-medical opioid use among those with cannabis use [70].

A practical challenge that can lead to unintended harm in co-use of cannabis and opioids is that opioid prescribing guidelines typically recommend a single prescriber (or team) who makes treatment decisions with the patient $[71,72]$. In practice, a provider who offers medical cannabis certification is likely to be someone other than the opioid prescriber, giving rise to potential conflicts in treatment philosophies. The opioid prescriber's assessment of potential benefit and risk may differ from the cannabis certifier and the prescribers sometimes abruptly discontinue opioid therapy with evidence of cannabis use, whether certified or not $[73,74]$. Finally, issues of provider liability may become complex if a patient who has both an opioid prescriber and a medical cannabis certifier were to overdose.

\section{Cannabis for treatment of OUD}

Recently, some states have introduced the treatment of OUD as a medical indication for cannabis [75]. However, there is very little research examining the effectiveness of cannabis for this indication. Moreover, there are three evidence-based medication treatments for OUDmethadone, buprenorphine and naltrexone-each of which have robust data from randomized controlled trials (RCTs) demonstrating improvement in important patient- and public-health outcomes [14]. Given the existence of evidence-based therapies for OUD, the lack of research examining cannabis for this indication, and the potential harms we agree with other commentators that the use of cannabis for this indication is premature [75].

\section{Provider advice for individuals using cannabis}

There is currently not enough evidence to suggest that the long-term benefits of cannabis are likely to outweigh the harms, though our understanding of the balance of benefits and harms of cannabis is very likely to change as research accumulates. While there is no conclusive evidence to support providers' endorsement of widespread medicinal use of cannabis, the reality of clinical practice today is that patients have access to and are using cannabis, and it is the provider's duty to play a role in reducing any likelihood of harm.

When asking patients about cannabis use, it is important to do so in a routine, non-judgmental fashion, and to ask about it separately from illicit drug history because cannabis is legal in many parts of the country. The provider may also want to ask about the reasons for usewhether recreational, medical, or both-because the reason for use may influence its frequency and route of administration; for medical use, this also allows for follow-up to assess whether or not use for medical purposes is having the intended effect $[76,77]$. When a provider encounters a patient who uses cannabis, the first step is to determine the quantity, frequency, and route of administration, as well as assessing for CUD. There are no widely validated short CUD screeners, but one option is use of the three-item Cannabis Use Disorders-Short Form to assess for CUD [78], and if the results are positive the provider should follow up by assessing for CUD with DSM-5 criteria (see Table 3).

Treatment of CUD should include evidence-based behavioral therapies, such as cognitive-behavioral therapy and motivational enhancement therapy along with abstinence-based incentives, targeted at cannabis 
cessation [79]. While a number of pharmacotherapies for CUD have been evaluated-including gabapentin, $\mathrm{N}$-acetylcysteine, antidepressants, and cannabinoids-the evidence is currently not strong enough to support routine use of pharmacotherapy for CUD [80]. For patients who use cannabis, but do not meet criteria for CUD, providers should counsel them on potential harms and provide psychoeducation and behavioral support.

Given the risk of withdrawal with CUD, providers should counsel patients who continue to use cannabis to avoid frequent, heavy use. Indeed, simply outlining the symptoms of withdrawal such as depression, anxiety, insomnia, and restlessness may help patients avoid a dangerous cycle of self-medication for withdrawal symptoms. It is likely that THC in particular is responsible for many of the potential mental health harms, so providers should suggest that patients avoid high-THC products. Patients at risk for mental illness, especially psychotic spectrum disorders, should be counseled to avoid cannabis.

The formulation of cannabis and route of administration influence its potential adverse effects. Patients should be made aware of the potent metabolite and the delayed onset of action associated with edible products, and accordingly use low doses, and avoid rapid dose escalation. Cannabis naïve patients should be especially cautious with edible products, and all individuals should avoid dabbing altogether given the high potency and risk for adverse effects. Individuals should avoid frequent and long-term cannabis smoking, and long, deep breath holds during inhalation. Providers should warn against use of any unregulated product obtained outside of dispensaries, including products advertised as CBD-only, given the existence of dangerous synthetic cannabinoids, labeling inaccuracies, and the risk of severe illness such as vaping-related pulmonary illness.

For patients who are prescribed other central nervous system (CNS)-acting agents, including, for example opioids, benzodiazepines, muscle relaxants, and gabapentinoids, we would encourage prescribers of those medications to caution patients that the additive effect of cannabis on psychomotor slowing and other CNS side effects has not been well studied. We recommend a conservative approach whereby providers decrease CNS-acting agent polypharmacy (in safe, patient-centered ways) prior to or concomitant with patients initiating cannabis regimens.

\section{Providers' responsibility to public health}

With the changing landscape of cannabis legislation throughout the U.S., and more states legalizing recreational cannabis, medical providers need to mindfully frame discussions of cannabis use with patients and families. To counter the inaccurate public perception of cannabis as harmless, the medical community must be prepared to synthesize the evidence and deliver clear public messaging on the potential harms of cannabis use. Current evidence suggests that recreational cannabis use is associated with other substance use and SUDs; mental health conditions; impairment in memory, learning and attention; respiratory symptoms; motor vehicle crashes; and overdose injuries in pediatric populations $[3,25$, 81]. Conversely, advocates of legalization argue that the criminalization of cannabis has had substantial social justice and public health implications through contact of millions of Americans with the criminal justice system [82]. There were 8.2 million cannabis-related arrests from 2001 to 2010, with African Americans four times more likely to be arrested; most of these arrests were for simple possession [83]. The downstream effects of these arrests can be detrimental as the existence of a criminal record can act as barrier to employment, housing, and public services for those arrested [83]. Ultimately, legalization will help to mitigate some of these structural inequities. However, legalization must be accompanied by a concerted public health effort to counter the potential harms of cannabis use.

This is particularly important for adolescent and young adult populations because we know most harms are related to use of smoked cannabis products among individuals who began smoking in a heavy, habitual way in adolescence. Development of prevention messages geared to adolescents and young adults is vital. Data from the Monitoring the Future study, which is an annual survey of 8 th, 10th and 12th grade students in the U.S., suggests that for three decades there was an inverse relationship between perceived risk of cannabis and cannabis use among high school students. Over the last few years, perceived risk has continued to decline steeply but there has not been a concomitant further rise in use, creating an opportunity for the medical community to focus efforts on effective prevention interventions [84].

\section{Conclusions}

The changing landscape of cannabis legislation throughout the U.S. has had an impact on the prevalence and perceptions of safety and harms of cannabis use. With increasing frequency, patients are turning to providers to inquire about a full spectrum of cannabis effects: from medical use to potential harms. Given the widespread use of cannabis to manage symptoms of chronic pain at the same time as the country is facing an opioid epidemic, it is not uncommon for patients to have questions about use of cannabis and opioids for pain. It is imperative that primary care providers understand the evidence to engage in balanced discussions with patients. Additionally, primary care providers need to have tools 
to assess for problem cannabis use and have a mechanism for referring patients for treatment if indicated. It is crucial that the medical community deliver consistent, evidence-based assessment, treatment, prevention and harm-reduction messaging to dispel myths and prevent potential public health problems related to cannabis use.

\begin{abstract}
Abbreviations
ABCD: adolescent Brain Cognitive Development Study; AIDS: acquired immunodeficiency syndrome; CBD: cannabidiol; CUD: cannabis use disorder; DC: district of Columbia; DSM: diagnostic and Statistical Manual; ED: emergency department; FDA: food and Drug Administration; HIV: human immunodeficiency virus; NESARC: national Epidemiologic Survey on Alcohol and Related Conditions; NIH: national Institutes of Health; OUD: opioid use disorder; PTSD: post-traumatic stress disorder; RCT: randomized controlled trial; SUD: substance use disorder; THC: delta-9-tetrahydrocannabinol; U.S.: united States.
\end{abstract}

\section{Acknowledgements}

Not applicable.

\section{Authors' contributions}

All authors contributed to manuscript conception, design, drafting and editing. All authors read and approved the final manuscript.

\section{Funding}

DK and CA's time was supported by the Department of Veterans Affairs, Veterans Health Administration, Office of Research and Development, Quality Enhancement Research Initiative. The findings and conclusions in this document are those of the authors who are responsible for its contents; the findings and conclusions do not necessarily represent the views of the Department of Veterans Affairs or the United States government.

\section{Availability of data and materials}

Not applicable.

\section{Ethics approval and consent to participate}

Not applicable.

\section{Consent for publication}

Not applicable.

\section{Competing interests}

The authors declare that they have no competing interests.

\begin{abstract}
Author details
${ }^{1}$ VA Evidence Synthesis Program, VA Portland Healthcare System, Mail Code R\&D 71, 3710 SW US Veterans Hospital Road, Portland, OR 97239-2999, USA.

${ }^{2}$ Oregon Health \& Science University, 3181 SW Sam Jackson Park Rd., Portland, OR 97239, USA. ${ }^{3}$ Department of Internal Medicine, Yale School of Medicine, 333 Cedar Street, New Haven, CT 06510, USA. ${ }^{4}$ VA Connecticut Healthcare System, West Haven, CT 06516, USA.
\end{abstract}

Received: 17 May 2019 Accepted: 9 November 2019

Published online: 02 December 2019

\section{References}

1. Hartig H, Geiger A. About six-in-ten Americans support marijuana legalization. Pew Research Center. 2018. www.pewresearch.org/ fact-tank/2018/10/08/.

2. National Conference of State Legislatures. State Medical Marijuana Laws 2019. https://www.ncsl.org/research/health/state-medical-marijuanalaws.aspx. Accessed 8 Apr 2019.

3. National Academies of Sciences Engineering and Medicine. The Health Effects of Cannabis and Cannabinoids: The Current State of Evidence and
Recommendations for Research. Washington, DC: National Academies Press (US); 2017.

4. Compton WM, Han B, Hughes A, Jones CM, Blanco C. Use of marijuana for medical purposes among adults in the United States. J Am Med Assoc. 2017:317(2):209-10.

5. Schauer GL, King BA, Bunnell RE, Promoff G, McAfee TA. Toking, Vaping, and Eating for Health or Fun: Marijuana Use Patterns in Adults, US, 2014 Am J Prev Med. 2016;50(1):1-8.

6. Azofeifa A, Mattson ME, Schauer G, McAfee T, Grant A, Lyerla R. National estimates of marijuana use and related indicators-National Survey on Drug Use and Health, United States, 2002-2014. MMWR Surveillance Summaries. 2016;65(11):1-25.

7. MacCallum CA, Russo EB. Practical considerations in medical cannabis administration and dosing. Eur J Intern Med. 2018;49:12-9.

8. Herkenham M, Lynn AB, Little MD, Johnson MR, Melvin LS, de Costa BR, et al. Cannabinoid receptor localization in brain. Proc Natl Acad Sci USA. 1990;87:5.

9. Malit LA, Johnstone RE, Bourke DI, Kulp RA, Klein V, Smith TC. Intravenous delta9-Tetrahydrocannabinol: effects of ventilatory control and cardiovascular dynamics. Anesthesiology. 1975;42(6):666-73.

10. Food and Drug Administration. FDA Regulation of Cannabis and Cannabis-Derived Products: Questions and Answers (2 April 2019). https ://www.fda.gov/news-events/public-health-focus/fda-regulation-canna bis-and-cannabis-derived-products-questions-and-answers. Accessed 24 Sept 2019.

11. McPartland J. Cannabis sativa and Cannabis indica versus "Sativa" and "Indica". In: Chandra S, Lata H, ElSohly MA, eds. Cannabis sativa L.- botany and biotechnology. New York: Springer; 2017. p. 101-121.

12. Loflin $M$, Earleywine M. A new method of cannabis ingestion: the dangers of dabs? Addict Behav. 2014;39(10):1430-3.

13. Monte AA, Shelton SK, Mills E, Saben J, Hopkinson A, Sonn B, et al. Acute illness associated with cannabis use, by route of exposure: an observational study. Ann Intern Med. 2019. https://doi.org/10.7326/m18-2809.

14. Volkow ND, Baler R. Emergency department visits from edible versus inhalable cannabis. Ann Intern Med. 2019. https://doi.org/10.7326/ m19-0542.

15. Ridgeway G, Kilmer B. Bayesian inference for the distribution of grams of marijuana in a joint. Drug Alcohol Depend. 2016;165:175-80.

16. Mariani JJ, Brooks D, Haney M, Levin FR. Quantification and comparison of marijuana smoking practices: blunts, joints, and pipes. Drug Alcohol Depend. 2011;113(2-3):249-51.

17. Vandrey R, Raber JC, Raber ME, Douglass B, Miller C, Bonn-Miller MO. Cannabinoid dose and label accuracy in edible medical cannabis products. JAMA. 2015;313(24):2491-3.

18. Bonn-Miller MO, Loflin MJE, Thomas BF, Marcu JP, Hyke T, Vandrey R. Labeling accuracy of cannabidiol extracts sold online. JAMA. 2017:318(17):1708-9.

19. Peiper NC, Gourdet C, Meinhofer A, Reiman A, Reggente N. Medical decision-making processes and online behaviors among cannabis dispensary staff. Subst Abuse. 2017. https://doi.org/10.1177/1178221817 725515.

20. Haug NA, Kieschnick D, Sottile JE, Babson KA, Vandrey R, Bonn-Miller MO. Training and practices of cannabis dispensary staff. Cannabis Cannabinoid Res. 2016;1 (1):244-51.

21. Leafly. Qualifying Conditions for a Medical Marijuana Card by State 2018. https://www.leafly.com/news/health/qualifying-conditions-for-medic al-marijuana-by-state. Accessed 12 Mar 2019.

22. Boehnke KF, Gangopadhyay S, Clauw DJ, Haffajee RL. Qualifying conditions of medical cannabis license holders in The United States. Health Aff. 2019;38(2):295-302.

23. Bonn-Miller MO, Boden MT, Bucossi MM, Babson KA. Self-reported cannabis use characteristics, patterns and helpfulness among medical cannabis users. Am J Drug Alcohol Abuse. 2014;40(1):23-30.

24. United States Drug Enforcement Administration. Drug Scheduling. https ://www.dea.gov/drug-scheduling. Accesssed 24 Sept 2019.

25. Nugent SM, Morasco BJ, O'Neil ME, Freeman M, Low A, Kondo K, et al. The effects of cannabis among adults with chronic pain and an overview of general harms: a systematic review. Ann Intern Med. 2017;167(5):319-31.

26. Stockings E, Campbell G, Hall WD, Nielsen S, Zagic D, Rahman R, et al. Cannabis and cannabinoids for the treatment of people with chronic 
noncancer pain conditions: a systematic review and meta-analysis of controlled and observational studies. Pain. 2018;159(10):1932-54.

27. Kansagara D, O'Neil M, Nugent S, Freeman M, Low A, Kondo K, Elven C, Zakher B, Motu'apuaka M, Paynter R, Morasco BJ. Benefits and harms of cannabis in chronic pain or post-traumatic stress disorder: a systematic review. VA ESP Project \#05-225; 2017.

28. Smith LA, Azariah F, Lavender VTC, Stoner NS, Bettiol S. Cannabinoids for nausea and vomiting in adults with cancer receiving chemotherapy. Cochrane Database Syst Rev. 2015. https://doi.org/10.1002/14651858. CD009464.pub2.

29. Devinsky O, Cross JH, Laux L, Marsh E, Miller I, Nabbout R, et al. Trial of cannabidiol for drug-resistant seizures in the dravet syndrome. N Engl J Med. 2017;376(21):2011-20.

30. Devinsky O, Patel AD, Cross JH, Villanueva V, Wirrell EC, Privitera M, et al. Effect of cannabidiol on drop seizures in the Lennox-Gastaut syndrome. N Engl J Med. 2018;378(20):1888-977.

31. Bergamaschi MM, Queiroz RH, Chagas MH, de Oliveira DC, De Martinis BS, Kapczinski F, et al. Cannabidiol reduces the anxiety induced by simulated public speaking in treatment-naive social phobia patients. Neuropsychopharmacology. 2011;36(6):1219-26.

32. Hurd YL, Spriggs S, Alishayev J, Winkel G, Gurgov K, Kudrich C, et al. Cannabidiol for the reduction of cue-induced craving and anxiety in drug-abstinent individuals with heroin use disorder: a double-blind randomized placebo-controlled trial. Am J Psychiatry. 2019. https://doi. org/10.1176/appi.ajp.2019.18101191.

33. Hasin DS. US epidemiology of cannabis use and associated problems. Neuropsychopharmacology. 2017;43:195.

34. Blanco C, Hasin DS, Wall MM, Florez-Salamanca L, Hoertel N, Wang S, et al. Cannabis use and risk of psychiatric disorders: prospective evidence from a US National Longitudinal Study. JAMA Psychiatry. 2016;73(4):388-95.

35. Hasin DS, Kerridge BT, Saha TD, Huang B, Pickering R, Smith SM, et al. Prevalence and correlates of DSM-5 cannabis use disorder, 2012-2013: findings from the national epidemiologic survey on alcohol and related conditions-III. Am J Psychiatry. 2016;173(6):588-99.

36. Lopez-Quintero C, Cobos J, Hasin DS, Okuda M, Wang S, Grant BF, et al. Probability and predictors of transition from first use to dependence on nicotine, alcohol, cannabis, and cocaine: results of the National Epidemiologic Survey on Alcohol and Related Conditions (NESARC). Drug Alcohol Depend. 2011;115(1-2):120-30.

37. Wall MM, Liu J, Hasin DS, Blanco C, Olfson M. Use of marijuana exclusively for medical purposes. Drug Alcohol Depend. 2019;195:13-5.

38. Metrik J, Gunn RL, Jackson KM, Sokolovsky AW, Borsari B.Daily patterns of Marijuana and alcohol co-use among individuals with alcohol and cannabis use disorders. Alcoholism. 2018;42(6):1096-104.

39. Volkow ND, Swanson JM, Evins AE, DeLisi LE, Meier MH, Gonzalez R, et al. Effects of cannabis use on human behavior, including cognition, motivation, and psychosis: a review. JAMA Psychiatry. 2016;73(3):292-7.

40. Hudak M, Severn D, Nordstrom K. Edible cannabis-induced psychosis: intoxication and beyond. Am J Psychiatry. 2015;172(9):911-2.

41. Meier MH, Caspi A, Ambler A, Harrington H, Houts R, Keefe RS, et al. Persistent cannabis users show neuropsychological decline from childhood to midlife. Proc Natl Acad Sci USA. 2012;109(40):E2657-E26642664.

42. Adolescent Brain Cognitive Development Study. About the Study. https ://abcdstudy.org/about/. Accessed 24 Sept 2019.

43. Pletcher MJ, Vittinghoff E, Kalhan R, Richman J, Safford M, Sidney S, et al. Association between marijuana exposure and pulmonary function over 20 years. JAMA. 2012;307(2):173-81.

44. Tetrault JM, Crothers K, Moore BA, Mehra R, Concato J, Fiellin DA. Effects of marijuana smoking on pulmonary function and respiratory complications: a systematic review. Arch Intern Med. 2007;167(3):221-8.

45. Christiani DC. Vaping-Induced Lung Injury. N Engl J Med. 2019.

46. Jones RT. Cardiovascular system effects of marijuana. J Clin Pharmacol. 2002:42(S1):58s-63s.

47. Ravi D, Ghasemiesfe M, Korenstein D, Cascino T, Keyhani S. Associations between marijuana use and cardiovascular risk factors and outcomes: a systematic review. Ann Intern Med. 2018;168(3):187-94.

48. Asbridge M, Hayden JA, Cartwright JL. Acute cannabis consumption and motor vehicle collision risk: systematic review of observational studies and meta-analysis. Br Med J. 2012;344:e536.

49. Rogeberg O, Elvik R. The effects of cannabis intoxication on motor vehicle collision revisited and revised. Addiction. 2016;111(8):1348-59.
50. Simonetto DA Oxentenko AS, Herman ML Szostek JH Cannabinoid hyperemesis: a case series of 98 patients. Mayo Clin Proc. 2012:87(2):114-9.

51. Richards JR, Gordon BK, Danielson AR, Moulin AK. Pharmacologic treatment of cannabinoid hyperemesis syndrome: a systematic review. Pharmacotherapy. 2017;37(6):725-34.

52. Wang GS, Le Lait MC, Deakyne SJ, Bronstein AC, Bajaj L, Roosevelt G. Unintentional pediatric exposures to Marijuana in Colorado, 2009-2015. JAMA Pediatr. 2016:170(9):e160971.

53. Wang GS, Roosevelt G, Le Lait MC, Martinez EM, Bucher-Bartelson B, Bronstein AC, et al. Association of unintentional pediatric exposures with decriminalization of Marijuana in the United States. Ann Emerg Med. 2014;63(6):684-9.

54. Wang GS, Hoyte C, Roosevelt G, Heard K. The continued impact of marijuana legalization on unintentional pediatric exposures in colorado. Clin Pediatr (Phila). 2019;58(1):114-6.

55. Armenian P, Darracq M, Gevorkyan J, Clark S, Kaye B, Brandehoff NP. Intoxication from the novel synthetic cannabinoids AB-PINACA and ADB-PINACA: a case series and review of the literature. Neuropharmacology. 2018;134(Pt A):82-91.

56. Adams AJ, Banister SD, Irizarry L, Trecki J, Schwartz M, Gerona R. "Zombie" outbreak caused by the synthetic cannabinoid AMB-FUBINACA in New York. N Engl J Med. 2017;376(3):235-42.

57. Winton A. New Haven Overdoses Tied to Laced K2. The New York Times. 2018.

58. Guy GP Jr, Zhang K, Bohm MK, Losby J, Lewis B, Young R, et al. Vital signs: changes in opioid prescribing in the United States, 2006-2015. Morbidity Mortality Weekly Report. 2017;66(26):697-704.

59. Bradford AC, Bradford WD. Medical marijuana laws may be associated with a decline in the number of prescriptions for medicaid enrollees. Health Aff. 2017:36(5):945-51.

60. Shi Y. Medical marijuana policies and hospitalizations related to Marijuana and opioid pain reliever. Drug Alcohol Depend. 2017:173:144-50.

61. Bachhuber MA, Saloner B, Cunningham CO, Barry CL. Medical cannabis laws and opioid analgesic overdose mortality in the United States, 1999-2010. JAMA Internal Med. 2014;174(10):1668-733.

62. Shover CL, Davis CS, Gordon SC, Humphreys K. Association between medical cannabis laws and opioid overdose mortality has reversed over time. Proc Natl Acad Sci USA. 2019;1 16(26):12624-6.

63. Abrams DI, Couey P, Shade SB, Kelly ME, Benowitz NL. Cannabinoid-opioid interaction in chronic pain. Clin Pharmacol Ther. 2011;90(6):844-51.

64. Cooper ZD, Bedi G, Ramesh D, Balter R, Comer SD, Haney M. Impact of co-administration of oxycodone and smoked cannabis on analgesia and abuse liability. Neuropsychopharmacology. 2018;43(10):2046-55.

65. Boehnke KF, Litinas E, Clauw DJ. Medical cannabis use is associated with decreased opiate medication use in a retrospective cross-sectional survey of patients with chronic pain. J Pain. 2016;17(6):739-44.

66. Boehnke KF, Scott JR, Litinas E, Sisley S, Williams DA, Clauw DJ. Pills to pot: observational analyses of cannabis substitution among medical cannabis users with chronic pain. J Pain. 2019;20(7):830-41.

67. Becker WC, Tetrault JM. Medical Marijuana in patients prescribed opioids: a cloud of uncertainty. Mayo Clin Proc. 2016;91 (7):830-2.

68. Chou R, Turner JA, Devine EB, Hansen RN, Sullivan SD, Blazina I, et al. The effectiveness and risks of long-term opioid therapy for chronic pain: a systematic review for a National Institutes of Health Pathways to Prevention Workshop. Ann Intern Med. 2015;162(4):276-86.

69. Reisfield GM, Wasan AD, Jamison RN. The prevalence and significance of cannabis use in patients prescribed chronic opioid therapy: a review of the extant literature. Pain Med. 2009;10(8):1434-41.

70. Olfson M, Wall MM, Liu SM, Blanco C. Cannabis use and risk of prescription opioid use disorder in the United States. Am J Psychiatry. 2018;175(1):47-53.

71. Dowell D, Haegerich TM, Chou R. CDC guideline for prescribing opioids for chronic pain_United States, 2016. J Am Med Assoc. 2016;315(15):1624-45.

72. Department of Veterans Affairs/Department of Defense. VA/DoD clinical practice guideline for opioid therapy for chronic pain. 2017. https ://www.healthquality.va.gov/guidelines/Pain/cot/VADoDOTCPG02271 7.pdf. Accessed 24 Sept 2019. 
73. Morasco BJ, Krebs EE, Adams MH, Hyde S, Zamudio J, Dobscha SK. Clinician response to aberrant urine drug test results of patients prescribed opioid therapy for chronic pain. Clin J Pain. 2019;35(1):1-6.

74. Gaither JR, Gordon K, Crystal S, Edelman EJ, Kerns RD, Justice AC, et al. Racial disparities in discontinuation of long-term opioid therapy following illicit drug use among black and white patients. Drug Alcohol Depend. 2018;192:371-6.

75. Humphreys K, Saitz R. Should physicians recommend replacing opioids with cannabis? J Am Med Assoc. 2019:321(7):639-40.

76. Boehnke KF, Scott JR, Litinas E, Sisley S, Clauw DJ, Goesling J, et al. Cannabis use preferences and decision-making among a cross-sectional cohort of medical cannabis patients with chronic pain. J Pain. 2019. https://doi. org/10.1016/j.jpain.2019.05.009.

77. Lin LA, Ilgen MA, Jannausch M, Bohnert KM. Comparing adults who use cannabis medically with those who use recreationally: results from a national sample. Addict Behav. 2016;61:99-103.

78. Bonn-Miller MO, Heinz AJ, Smith EV, Bruno R, Adamson S. Preliminary development of a brief cannabis use disorder screening tool: the cannabis use disorder identification test short-form. Cannabis Cannabinoid Res. 2016;1(1):252-61

79. Gates PJ, Sabioni P, Copeland J, Foll B, Gowing L. Psychosocial interventions for cannabis use disorder. Cochrane Database Syst Rev. 2016:5:005336.
80. Kondo K, Morasco BJ, Nugent S, Ayers C, O'Neil ME, Freeman M, et al. Pharmacotherapy for the treatment of cannabis use disorder: a systematic review. VA ESP Project \#05-225. 2018.

81. Volkow ND, Baler RD, Compton WM, Weiss SRB. Adverse health effects of marijuana use. N Engl J Med. 2014;370(23):2219-27.

82. Drug Policy Alliance. From prohibition to progress: a status report on marijuana legalization. 2018. drugpolicy.org/legalization-status-report. Accessed 24 Sept 2019.

83. American Civil Liberties Union. Marijuana Arrests by the Numbers.

84. Johnston LD, O'Malley PM, Miech RA, Bachman JG, Schulenberg JE. Monitoring the future national survey results on drug use, 1975-2015: Overview, key findings on adolescent drug use. In: Institute for Social Research, ed. Ann Arbor; 2016.

85. American Psychiatric Association. Substance-related and addictive disorders. diagnostic and statistical manual of mental disorders. DSM Library, American Psychiatric Association; 2013.

\section{Publisher's Note}

Springer Nature remains neutral with regard to jurisdictional claims in published maps and institutional affiliations.
Ready to submit your research? Choose BMC and benefit from:

- fast, convenient online submission

- thorough peer review by experienced researchers in your field

- rapid publication on acceptance

- support for research data, including large and complex data types

- gold Open Access which fosters wider collaboration and increased citations

- maximum visibility for your research: over $100 \mathrm{M}$ website views per year

At BMC, research is always in progress.

Learn more biomedcentral.com/submissions 